Publisher: ELSEVIER SCIENCE BV, PO BOX 211, 1000 AE AMSTERDAM, NETHERLANDS

Subject Category: Chemistry, Analytical

DOI:10.1016/S0039-9140(02)00612-4

ISSN: 0039-9140

http://www.sciencedirect.com/science? ob=ArticleURL\& udi=B6THP-47RBSK8$6 \&$ user $=2347467 \&$ coverDate $=03 \% 2 F 10 \% 2 F 2003 \&$ alid $=1140645672 \&$ rdoc $=4 \&$ fmt $=$ high \& orig $=$ search\&_cdi $=5288 \&$ sort $=r \&$ docanchor $=\& v i e w=c \&$ ct $=6 \&$ _acct $=$ C000057013\&_version $=1 \&$ _urlVersion= 0\&_userid $=2347467 \& \mathrm{md} 5=\mathrm{a} \overline{4} \mathrm{c} 178 \mathrm{f} 16 \mathrm{cee} 0680 \mathrm{c} 117 \mathrm{f} 2 \mathrm{aa}$ ca $\overline{7} \mathrm{e} 828$

\title{
DETERMINATION OF ETHANOL IN BEVERAGES BY FLOW INJECTION, PERVAPORATION AND DENSITY MEASUREMENTS
}

\section{J. González-Rodríguez ${ }^{1}$, P. Pérez-Juan ${ }^{1}$ and M.D. Luque de Castro ${ }^{2 *}$}

${ }^{1}$ R\&D Department Pérez Barquero, S.A. Avda. de Andalucía, 27, E-14550, Montilla, Córdoba, Spain. Fax: 957 650208, E-mail: barquero@fiab.es

${ }^{2}$ Analytical Chemistry Division, Campus of Rabanales. Annex C-3 Córdoba. Spain. Fax: 34-957-218615, E-mail: qa1lucam@uco.es

*Corresponding author

A fast, clean and easy to automate flow injection-pervaporation method for the determination of ethanol in different beverages using density measurements is proposed. The method is based on separation of the ethanol from the sample using a pervaporation module, thus obtaining in the acceptor chamber of the pervaporator a water-alcohol mixture, the density of which is measured. After optimisation by either the univariate or multivariate approach as required, a linear range between 0 $40 \%$ was established. Then, the assessment of the method versus a reference one was studied in terms of repeatability $(0.12 \% \mathrm{v} / \mathrm{v})$, reproducibility $(0.32 \% \mathrm{v} / \mathrm{v})$, detection limit $(0.11 \% \mathrm{v} / \mathrm{v})$ and traceability. The sample throughput was 15 samples $\mathrm{h}^{-1}$. The method was in agreement with the reference methods used in the European Union.

Keywords: ethanol, wine, brandy, spirits, pervaporation, flow injection, density measurements 


\section{Introduction}

Measurement of the ethanol percentage in water-alcohol mixtures, such as wine or spirits, is a key analytical parameter in the beverage industry. In fact, it is the most frequent analysis made in winery laboratories. The importance of the ethanol content in a beverage it is not only because it determines the quality and conservation of the product but also because both its high commercial value and the special taxes to which it is subjected in all countries. The latter is the main reason why the measurement of alcohol degree requires high accuracy and precision.

The most usual methods to determine the alcohol degree in wineries are based on previous distillation and measurement of the alcohol in the distillate using photometry [1] or titration [2] after chemical derivatisation with chromium (VI), areometry [3] or refractometry [4]. The official methods, based on areometry or picnometry [5], are slow and difficult to automate; the chemical method developed by Crowell and Ough [1], based on oxidation with chromium (VI) and frequently used as reference method, has an acceptable accuracy and precision but is even longer and tedious than the official ones because of the necessity for previous distillation. Other more scarcely used methods are based on ebullometry [6], -endowed with a low precision- and on measurements of surface tension which are highly influenced by the matrix of the target beverage and the working conditions of the analysis. Chromatographic methods [7], both GC and HPLC, are also used for the determination of this parameter, but the higher costs of acquisition and maintenance of the equipments do not justify the investment most times. Other technique used for this determination but that present irreproducibility due to the matrix of the beverage is the near infrared spectroscopy [8].

The aim of this work was to develop an easy to automate flow injection (FI) method, fast, cheap and with enough accuracy and precision by using analytical pervaporation for separation and a density-meter with a vibrating tube as detector. Pervaporation is a non chromatographic membrane-based separation technique which has for long been employed in the industry and that selectively separates a liquid mixture by partial vaporisation through a nonporous polymeric membrane. The separation is not based on relative volatilities, as in the case of distillation, but rather on the relative rates of permeation through the membrane. Analytical pervaporation can be defined as the combination of evaporation and gas diffusion in a single module $[9,10]$. In the case of the vibrating tube density detector an either straight or more usually U-shaped tube causes mechanical resonant vibrations. The square of the resonance frequency is then inversely proportional to the sum of the mass of tube and tube contents. As both the tube mass and the tube inner volume are known values, the vibrating tube method allows the density of unknown fluids to be 
determined in a single measurement, after the instrument has been calibrated with two fluids, usually water and air, which give low and high tones for high and low density, respectively. The Utube is kept oscillating continuously at the characteristic frequency, which depends on the density of the filled-in sample. The oscillation period is measured and converted into density by the equation of the Mass-Spring-Model: $\mathrm{F}=1 / 2 \pi \sqrt{ }[\mathrm{c} /(\mathrm{M}+\rho \mathrm{V})]$ where, $\mathrm{f}=$ =frequency, $\quad c=$ spring constant; $\quad \mathrm{M}=$ mass, $\rho=$ density; $V=$ volume

\section{Experimental}

\section{Apparatus and instruments}

The manifold used, depicted in Fig.1, was built using a four-channel Gilson Minipuls-3 peristaltic pump (Villiers le Bel, France) fitted with a rate selector, two Rheodyne 5041 injection valves (Elkay, Galway, Ireland) -one of them used as a selecting valve- and PTFE tubing of $0.5 \mathrm{~mm}$ i.d. (Análisis Vínicos, Tomelloso, Spain). A DMA 4500 digital density meter from Anton Paar (Graz, Austria) for data collection and treatment was also used.

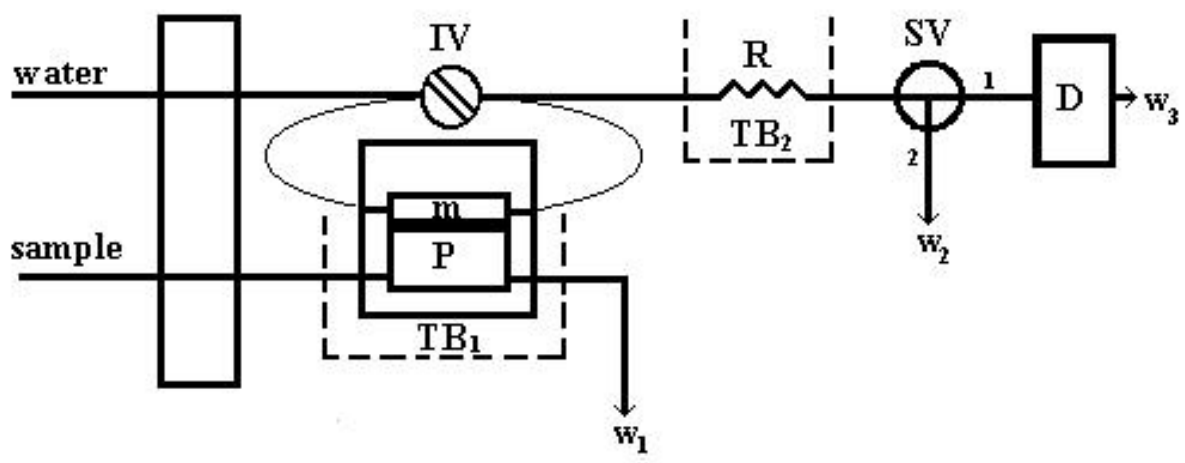

Figure 1. Manifold for the determination of ethanol. $S V=$ selection valve, $I V=$ injection valve, $\mathrm{R}=$ reactor, $\mathrm{D}=$ detector, $\mathrm{w}=$ waste, $\mathrm{m}=$ membrane, $\mathrm{TB}=$ thermostatic bath, $\mathrm{P}=$ pervaporation unit.

Two SBS model TFB-1 Selecta (Barcelona, Spain) thermostats, a laboratory-made pervaporation module, described elsewhere $[9,10]$ and PTFE membranes $(47 \mathrm{~mm}$ diameter, $1,5 \mathrm{~mm}$ thickness) from Trace (Braunschweig, Germany) were used.
Statistical treatments were made using Statgraphics $^{\mathrm{TM}} 2.1$ plus for Windows.

A Distillatore Elettronico Enochimico (Gibertini, Milan, Italy) based on water steam dragging was used for sample distillation. A Cary 50 Conc 
spectrophotometer and connected to a computer with Cary WinUV v. $2.0^{\circledR}$ (Varian, Mulgrave, Australia) software for data collection and treatment was also used for the determination of ethanol in vinegar.

\section{Reagents and solutions}

An aqueous solution of $33.608 \mathrm{~g} \mathrm{l}^{-1}$ of potassium dichromate (Panreac, Barcelona, Spain), $135 \mathrm{~g} \mathrm{l}^{-1}$ of ammonium iron (II) sulphate hexahydrate (Panreac) in 0.4 sulphuric acid (Panreac), an aqueous solution of $9.5 \mathrm{M}$ sulphuric acid (Panreac), an aqueous solution of $6.95 \mathrm{~g} \mathrm{l}^{-1}$ iron (II) sulphate heptahydrate with $14.85 \mathrm{~g} \mathrm{l}^{-1}$ of 1,10-phenanthroline used as indicator, and a $4 \mathrm{M}$ solution of calcium hydroxide were used.

\section{Reference procedures}

\section{Reference method for ethanol in vinegar}

The method is based on the photometric detection of $\mathrm{Cr}^{+3}$ at $600 \mathrm{~nm}$, formed by oxidation of ethanol after distillation of the vinegar. Sodium hydroxide was added to $200 \mathrm{ml}$ of vinegar up to $\mathrm{pH}$ 10-11 and then distilled and collected in a $100 \mathrm{ml}$ volumetric flask. A volume of $20 \mathrm{ml}$ of diluted sulphuric acid and 20 $\mathrm{ml}$ of potassium dichromate were added to $10 \mathrm{ml}$ of distillate and the mixture was allowed to stand for $30 \mathrm{~min}$. The excess of potassium dichromate was titrated with ammonium iron(II) sulphate in the presence of $1,10-$ phenanthroline.

\section{Reference method for ethanol in wine}

Calcium hydroxide and pumice stone were added to $200 \mathrm{ml}$ of wine and then distilled and the distillate collected in a $200 \mathrm{ml}$ volumetric flask. A volume of 198-199 ml of distillate was collected when distillation is made in a steam dragging apparatus and filled to $200 \mathrm{ml}$ with water and at the same temperature that the raw wine $\left( \pm 2^{\circ} \mathrm{C}\right)$. The determination of the alcoholic content in the distillate was made using density measurements at $20^{\circ} \mathrm{C}$.

Reference method for ethanol in brandy and spirits

The procedure is the same as in the case of wine but without adding calcium hydroxide.

\section{Proposed procedure}

The sample was introduced into the dynamic manifold shown in Fig. 1 by aspiration and pumped into the donor chamber of the pervaporation unit. The ethanol was pervaporated and collected into distilled water used as acceptor, which remained static by keeping valve IV in its filling position. Meanwhile, the selecting valve SV was in position (2). After an interval for sufficient enrichment of the static acceptor with the pervaporated species ( $3 \mathrm{~min}$ from sample introduction) valve IV was switched to the injection position, SV switched to position (1) and the plug led to the density meter. When the plug was in the measuring cell, SV was switched to position (2) for maintaining static the plug in the detector in order to allow its adjustment at $20^{\circ} \mathrm{C}$ and then 
measurement of the density. In the meantime, cleaning and introduction of a new sample into the dynamic is performed. The density data are automatically converted (including temperature compensation of the detector if necessary) into alcohol concentration using the built-in conversion tables.

\section{Results and discussion}

\section{Optimisation of the method}

The variables which affect the method for the determination of alcohol degree were studied by either the multivariate or univariate approaches depending on either the interrelation or independence between variables. The range studied and the optimal values found are shown in Table 1.

Table 1. Optimisation of variables

\begin{tabular}{lll}
\hline Variable & $\begin{array}{c}\text { Tested } \\
\text { range }\end{array}$ & $\begin{array}{c}\text { Optimum } \\
\text { value }\end{array}$ \\
\hline$\underline{F I}$ & & \\
$\mathrm{Q}_{1}=\mathrm{Q}_{2}\left(\mathrm{ml} \mathrm{min}^{-1}\right)$ & $0.4-3.0$ & 2.2 \\
$\mathrm{R}_{1}(\mathrm{~cm})$ & $50-200$ & 100 \\
$\underline{\text { Pervaporation }}$ & & \\
$\mathrm{T}\left({ }^{\circ} \mathrm{C}\right) \mathrm{TB}_{1}$ & $60-90$ & 85 \\
$\mathrm{~T}\left({ }^{\circ} \mathrm{C}\right) \mathrm{TB}_{2}$ & $15-20$ & 17 \\
$\mathrm{t}(\min )$ & $1-5$ & 3 \\
\hline
\end{tabular}

Figure 2 shows a plot of the percentage of alcohol versus both the temperature of the thermostatic bath and flow-rate. The R-squared statistic indicates that the model explains $97.55 \%$ of the variability in alcohol content. The equation of the fitted model is: alcohol $(\% \mathrm{v} / \mathrm{v})=-15.33+$ $0.308 \mathrm{~T}-0.571 \mathrm{~F}^{2}+0.013 \mathrm{FT}-7.9 \times 10^{-}$ ${ }^{5} \mathrm{~T}^{2}$, where $\mathrm{T}$ and $\mathrm{F}$ are temperature and flow-rate, respectively. The temperature is a more influential parameter than the flow-rate, as can be observed in the figure: the highest alcohol percentages were obtained at low flow rates and high temperature. The temperature had a marked influence on the efficiency of the pervaporation process as its increase promoted a higher vapour pressure of the analyte and, therefore, a higher mass transfer through the membrane. A temperature of $85^{\circ} \mathrm{C}$ and a flow-rate of $2.2 \mathrm{ml} \mathrm{min}^{-1}$ were selected as a compromise between sensitivity and sampling frequency. The reactor $\mathrm{R}$ (plunged in the thermostatic bath $\mathrm{TB}_{2}$ in Fig.1) had the function of cooling the acceptor stream after leaving the pervaporator and before reaching the density-meter in order to set the temperature as closer as possible to $20^{\circ} \mathrm{C}$. A temperature of $17^{\circ} \mathrm{C}$ in the thermostatic bath and an $\mathrm{R}$ value of $1 \mathrm{~m}$ were sufficient for this purpose. The efficiency of the pervaporation was favoured by stopping the acceptor solution, thus achieving a higher enrichment by a mass-transfer closer to equilibrium. The pervaporation time, during which the acceptor solution remained static, was tested between 1 and $5 \mathrm{~min}$. The analytical signal increased with longer intervals as the efficiency of pervaporation was favoured. A static time of $3 \mathrm{~min}$ was chosen as a compromise between sensitivity and sampling rate. 


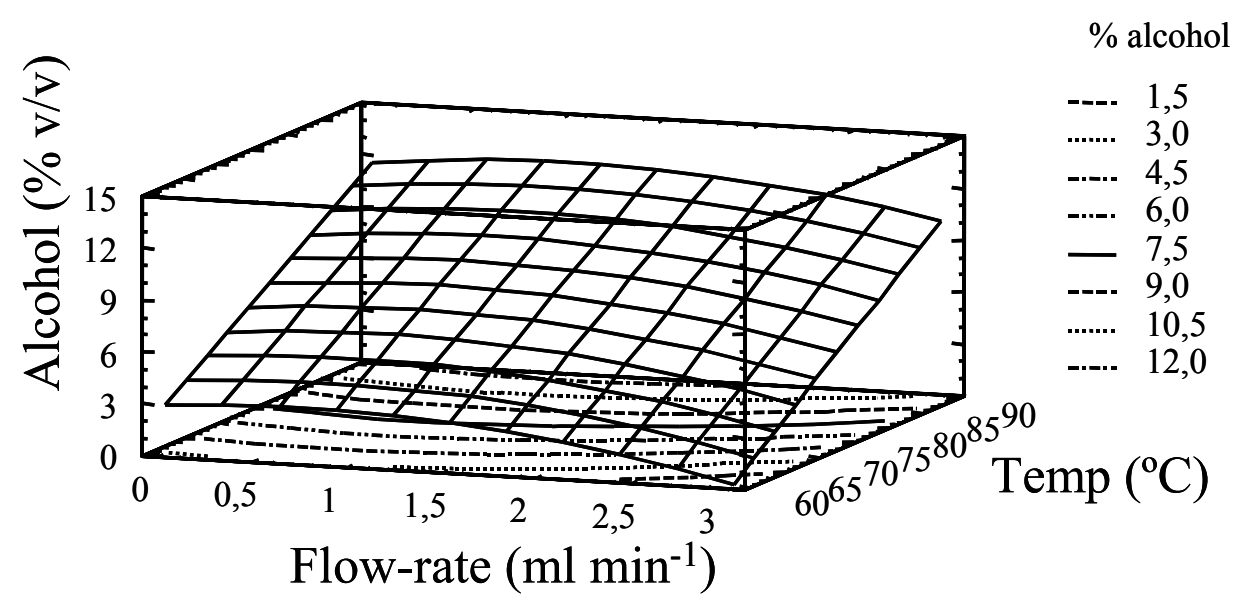

Figure 2. Response surface of the multivariate analysis: evolution of alcohol content (\% $\mathrm{v} / \mathrm{v})$ versus temperature of the pervaporation unit $\left({ }^{\circ} \mathrm{C}\right)$ and the flow-rate $\left(\mathrm{ml} \mathrm{min}^{-1}\right)$ in the upper chamber of the pervaporation unit.

\section{Characterisation of the method}

No calibration curves were run using standard solutions due to the features of the density-meter. Density values of water-alcohol solutions are automatically transformed into an estimated alcohol content by internal conversion tables at $20{ }^{\circ} \mathrm{C}$. Thus, the alcohol degree is obtained without a previous calibration.

The linear range of the method was calculated using target samples of known concentration established by the reference method.

\section{Assessment of the proposed method}

Thirty different samples of brandy, wine, whisky, vodka and vinegar were used in the assessment study. Each datum was the average of three determinations. The assessment study involved analytical parameters such traceability with a reference method, repeatability, reproducibility, detection and quantification limits and sample throughput. A robustness study was also developed.

Repeatability ( $r$ ).The F-test was applied in order to establish if the differences between repeatability of the methods were significant. With this aim, the Fobs $=\mathrm{S}_{\mathrm{r}}^{2} / \mathrm{S}_{\mathrm{ref}}^{2}$ was compared with the $\mathrm{F}_{1-\alpha}$ obtained from $\mathrm{F}$ tables for $\alpha=0.05(\mathrm{P}=95 \%)$. As can be observed in Table 2, Fobs $<F_{1-\alpha}$, so there are not significant differences between the repeatability of both methods. 
Table 2. Analytical characteristics of the proposed method as compared with the reference method

\begin{tabular}{lll}
\hline Parameters & Reference & Flow injection \\
\hline Repeatability $(\% \mathrm{v} / \mathrm{v})$ & 0.097 & 0.123 \\
$\mathrm{~S}_{\underline{\underline{\underline{r}}}}(\% \mathrm{v} / \mathrm{v})$ & 0.035 & 0.045 \\
Reproducibility $(\% \mathrm{v} / \mathrm{v})$ & 0.210 & 0.324 \\
$\mathrm{~S}_{\underline{\underline{R}}}(\% \mathrm{v} / \mathrm{v})$ & 0.085 & 0.113 \\
Fobs $^{\mathrm{r}}$ & - & 1.74 \\
Fobs $^{\mathrm{R}}$ & - & 1.77 \\
$\mathrm{~F}_{1-\alpha}(\mathrm{n}=30)$ & 1.84 & 1.84 \\
LOD $(\% \mathrm{v} / \mathrm{v})$ & 0.034 & 0.112 \\
Sample throughput $\left(\mathrm{h}^{-1}\right)$ & 4 & 15 \\
\hline
\end{tabular}
$\mathrm{S}^{2} / \mathrm{S}_{\mathrm{ref}}^{2}$

Reproducibility ( $R$ ) (30 days).Table 2 also shows the $\mathrm{R}$ values obtained as well as the results from the application of the F-test. The reproducibility of the FI method is slightly lower than that of the reference method but both methods are statistically equal.

Detection limits (LOD). Table 2 shows that the best LOD corresponds to the reference method but the value provided by the FI method is enough for the analysis requirements as the linear range includes the concentrations of ethanol in all samples.

Traceability.Prior to the traceability study, adjustment of the raw data from the proposed method was mandatory due to the fact that, meanwhile in the reference method quantitative separation of ethanol is performed by distillation, in the proposed method partition of the analyte between the liquid sample and the gas headspace, between this and the membrane and between the membrane and the acceptor solution is established. The adjustment provided the following correlation equation: $\mathrm{Y}=0.334 \mathrm{X}+4.343$, which presented an excellent correlation $\left(r^{2}=0.999\right)$. The traceability of the method was studied by comparing the results obtained from the 30 samples analysed by both the reference and proposed method. Figure 3 shows the regression of the flow injection method on the reference method for ethanol determination. The regression equation, $\mathrm{Y}=1.004 \mathrm{X}+0.03$, shows good correlation $\left(r^{2}=0.994\right)$ between the data from both methods. Confidence limits of $95 \%$ are shown in Fig. 3 in dotted lines. In both cases, the traceability was assured using the $\mathrm{t}$-test. 
Sample throughput.The results in Table 2 show that the FI method has a sampling frequency much higher than that of the reference method (15 vs $4 \mathrm{~h}^{-}$ $\left.{ }^{1}\right)$ and also better than other methods such as those based on pycnometry or the hydrostatic balance which require hours for a single measurement.

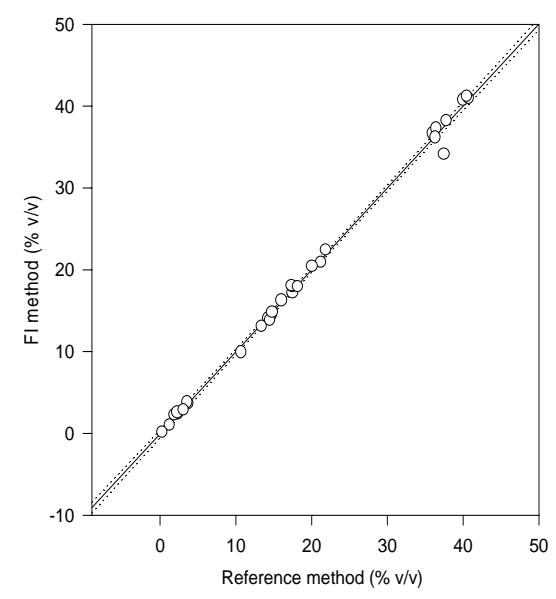

Figure 3. Correlation graph of the reference method with the FI method for ethanol. Interval of confidence: $95 \%$.

Robustness study. The study was developed using the YoundenSteiner [11] procedure. Critical variables of the system are the flowrate and temperature of the pervaporation unit. These variables were modified $\pm 10 \%$ from their optimum values. Errors lower than 7 and 20\% were observed for the flow-rate and temperature, respectively.

\section{Conclusions}

The method proposed here enables the determination of the alcohol degree in very different kind of beverages, with the characteristic advantages of the FI methods and also of the two main constituents of the overall approach, namely the density-meter and the pervaporation unit. Thus, the advantages of using a density-meter based on the oscillating U-tube technique are, higher precision and extremely fast measurements ( 1 min measurement ${ }^{-1}$ ). The advantages of using pervaporation for separation are mainly the wide field of application to the analysis of samples where the ethanol separation from the matrix is required and the capability for automation in a simple, rapid and robust way. Thus, pervaporation is a valid alternative to manual distillation, saving thus time and costs. The proposed method is easy to use, inexpensive, presents a good correlation with the reference method commonly used and can be easily implemented in a winery laboratory for monitoring ethanol in all kind of beverages because of its high reproducibility and repeatability over large concentration ranges. The manifold proposed increased the efficiency of laboratory operations and throughput of analyses.

\section{Acknowledgements}

The Spanish Comisión Interministerial de Ciencia y Tecnología (CICyT) is thanked for financial support (Project BQU 2000/ 0241). Anton Paar is also thanked for technical and bibliographic support. 


\section{References}

[1] M. A. Amerine, C. S. Ough, Análisis de Vinos y Mostos, Ed. Acribia, Zaragoza, España, 1976, p.57.

[2] Recueil des méthodes internacionales d'analyse des vins et des mouts, Office International de la Vigne et du Vin (OIV), Paris, 1990.

[3] Diario Oficial de las Comunidades Europeas, L272, 33 año, 3 de octubre de 1990, p. 37.

[4] Diario Oficial de las Comunidades Europeas, L272, 33 año, 3 de octubre de 1990, p. 38.

[5] Diario Oficial de las Comunidades Europeas, L272, 33 año, 3 de octubre de 1990, p. 36.

[6] M. A. Amerine, C. S. Ough, Análisis de Vinos y Mostos, Ed. Acribia, Zaragoza, España, 1976, p.49.

[7] M. A. Amerine, C. S. Ough, Análisis de Vinos y Mostos, Ed. Acribia, Zaragoza, España, 1976, p.61.

[8] H. Q. Luo, S. P. Liu, FenxiHuaxue 28 (1998) 370.

[9] I. L. Mattos, M. D. Luque de Castro, Anal. Chim. Acta 298 (1994) 159.

[10] I. Papaesftathiou, M. D. Luque de Castro, Anal. Chim. Acta 354 (1997) 135.

[11] J. Younden, E. H. Steiner, Statistical Manual of the Association of Oficial Analytical Chemist (AOAC), AOAC, Washington DC, 1975. 
